Journal of History Culture and Art Research (ISSN: 2147-0626)

Tarih Kültür ve Sanat Araştırmaları Dergisi

Vol. 10, No. 3, September 2021

\title{
DOI: 10.7596/taksad.v10i3.3089
}

Citation: Soykunt, N., \& Gorgoretti, B. (2021). Student Opinions on Psychomotor Learning Activities Used in Music Lessons. Journal of History Culture and Art Research, 10(3), 27-36. doi: http://dx.doi.org/10.7596/taksad.v10i3.3089

\section{Student Opinions on Psychomotor Learning Activities Used in Music Lessons}

\author{
Neriman Soykunt ${ }^{1}$, Başak Gorgoretti ${ }^{2}$,
}

\begin{abstract}
This study aims to determine the situation by examining the opinions of 8th-grade students about psycho-motor activities used within the scope of 8th-grade music lessons. Semi-structured interview technique was used as a qualitative method in the research. With this method, data were collected by conducting one-on-one interviews with 8th-grade students. The study was conducted with forty-four 8th-grade students. The obtained data were analyzed by making content analysis. According to the findings obtained from the interviews; It is understood that the psycho-motor activities used in schools are mostly similar, but there are problems in the implementation process, the activities cannot be used effectively and efficiently, and music lesson activities are not given enough importance due to the problems arising from the deficiencies in the material and learning environment. From the students' opinions, it is understood that the theoretical parts of the music lessons are long and the lessons conducted in this way are boring. Based on the students' opinions, it is understood that the singing activity is the most used psycho-motor activity, but this activity is not used to improve the musical knowledge and skills taught in the lessons, but to increase the students' interest in the lessons. It is understood that rhythm exercises, body percussion and instrument playing activities are less involved in music lessons than singing activities.
\end{abstract}

Keywords: Body percussion, instrument playing, music education, psycho-motor skills, singing

\footnotetext{
${ }^{1}$ Near East University, https://orcid.org/0000-0002-9579-9518, E-mail: neriman.soykunt@neu.edu.tr

2 Eastern Mediterranean University, https://orcid.org/0000-0002-0656-0688,E-mail: basak.guler@emu.edu.tr
} 


\section{Introduction}

Music education is generally defined as the process of bringing musical behaviors to the individual, moreover, it changes and develops these behaviors (Uçan, 1997) Music education, when considered as a musical field, refers to the education of students to understand, create, develop auditory knowledge and skills in understanding their sounds, patterns in sound, relationships between sounds, rhythms, styles and forms decks (Petress, 2005). To put it simply, music education is a field of education in which music is learned, felt, practiced and taught.

With music education, students are given certain musical knowledge, skills and musical behaviors. Karakoç and Şendurur (2015) stated that musical behaviors intended to be acquired are 'singing, playing instruments, listening to music, musical hearing, producing music, creating music, expressing music with the body, interpreting and using music'.

In the study of these musical behaviors, it was noted that there is a need for teaching music based not only on theory but also on practice, so the importance of applying mainly musical practices to teaching stages of music teaching has been pointed out. Çuhadar (2016) argued that it is right to provide music education with active and student-centered learning/teaching environments in order to develop not only theoretical but also musical skills in order to gain musical behaviors, thus, he argued that it would be possible to raise individuals who create music, feel music, have fun with music and experience music.

Concina (2015) discusses music learning not only cognitively, but also in terms of affective and psychomotor learning and emphasizes that each area complements the other, psychomotor learning also affects cognitive learning, thus ensuring effective and lifelong learning. In this context, it is also understood the necessity of a learning process in which students are active and the importance of psycho-motor learning play a large role in the realization of effective music teaching. From this point of view, it is seen that the continued response and response of individuals to music through physical movements during and after the psychomotor development phase helps to feel and learn music (Pflederer, 1964).

When we look at the musical teaching approaches developed to feel, apply and experience music; it is understood that they have a common denominator in the learning and teaching of music lessons based on movement. Depending on the principle of learning by doing and living, it is considered that the courses in which students experience musical knowledge and skills are more permanent and the necessity of student-centered processing of music lessons is emphasized. Therefore, the importance of music teaching approaches developed for use in music education is also understood once again.

Looking at the movement-based music teaching approach developed by Swiss music educator and composer Dalcroze; it is understood that musical knowledge and skills are learned by reacting and responding to music with movements, music is expressed through experience, all concepts of music are taught with a movement-based approach. Hungarian music educator and composer Kodaly points out that the musical knowledge and skills experienced by the students are more permanent and also emphasizes that songs have an important place in learning these skills; that singing is the most important activity for experiencing and learning music (Richards, 2015). Music educator and composer Carl Orff took a holistic approach to music teaching; rhythm, dance and instrument and 
accompaniment works are carried out together. Orff, on the other hand, suggested that rhythm studies be applied through physical experiences, noting that the concept of rhythm is the most prominent feature of the music field and the most basic element in starting music education (Lewis, 1989). Applications such as "interpreting music with creative movements", "performing movement-based studies with ropes", "performing studies that increase movement technique, coordination, muscle memory, rapid response and rhythmic sensitivity" can be given as examples as motion-based musical activities in trainings based on the Orff approach (Lewis,1989).

When we look at musical activities where psycho-motor skills are used in school music education, singing, body percussion studies, instrument playing and creative dance, synchronous reactions to music, creating new movements, managing, accompanying the song with ostinato and many learning activities that we can express as psychomotor response, are the most common musical applications we encounter in the basic education level (1-8th grades) (Soykunt and Gorgoretti, 2019). Lewis points out that music activities based on physical activities that take place in the music class in his study (1989) are widely preferred in the course because they are perceived by students as an extension of fun and musical games. In their study, Brown and al. (1981) stated that the rhythmic studies used in music lessons were important support in the development of basic motor skills (such as jumping, climbing, catching) of students.

It is noticeable that the activities that are applied in the music lesson and in which students participate the most are activities that accompany cognitive learning, which are movement-based and appeal to psychomotor learning (Concina, 2015). It is seen that these activities not only improve students in the field of cognitive learning, but also in the field of social learning and gain self-confidence and self-esteem skills thanks to the roles they acquire (Güleç, 2007). Therefore, the importance and role of each psycho-motor activity used in music lessons is undeniable.

When looking at the 1-8th grades music course curriculum in Northern Cyprus; it is seen that psycho-motor activities are more common in the first-tier classrooms of primary education and are sparse in the grades in the second tier of primary education. Based on this finding, it is thought that there are restrictions and problems related to music lessons and psycho-motor activities carried out in the 2 nd level of primary education; Based on this idea, the research aims to determine the views of the second-tier eighth graders about the psychomotor activities used in music lessons.

\section{Method}

\section{Research Pattern}

This research was carried out using the phenomenology research design. Phenomenology research allow us to achieve results that will help us better understand and recognize a case or situation. It is possible to obtain results that can express and reflect the case by using the interview technique with people who are experiencing the phenomenon and who are in it one-on-one in fact science research (Yıldırım \& Şimşek, 2016).

Psychomotor activities in music education constitute the study phenomenon. In order to present and examine this phenomenon in the best way and to drill down, the phenomenology design was used. In this context, research was carried out using qualitative methods in order to reveal the necessary phenomenon in a clearer and more detailed way. 


\section{Participants}

The environment of the research is made up of all eighth-grade students studying in the second tier (Secondary School) of the Ministry of National Education in 5 different districts of Northern Cyprus. The sample of the study consisted of 44 students selected by random sample from 11 secondary schools in Famagusta and Iskele districts. The students interviewed were selected entirely on a 'voluntary basis'.

\section{Data Collection Tools and Data Collection Process}

A semi-structured interview form was used to determine the opinions of 8th-grade students regarding psycho-motor activities used within the scope of the 8th-grade music course.

A semi-structured interview technique is an interview technique in which the researcher can ask different or unforeseen questions depending on the course of the interview, enabling the interviewer to explain or configure their answers. Thus, it is one of the most preferred methods to ensure that participants give clearer and more accurate answers (Türnüklü, 2000).

The students were asked the following 6 questions during the interview:

1) What are the methods and techniques used by your music teacher during the lesson?

2) Does your music teacher include Psychomotor learning activities in the course? Can you give an example of these activities?

3) For what purpose do you think your teacher is practicing these activities?

4) What are your ideas and opinions about these events?

5) How do you feel during the activities?

6) Do you experience any setbacks or difficulties in the implementation of these activities in the classroom?

\section{Data Analysis}

Content analysis method was used to analyze qualitative data. Descriptive and revealing information and concepts were tried to be reached from the data obtained by this method. The content analysis conducted consisted of the stages of defining, coding categorization, classification and naming the repeated themes in the data set, considering the basic steps suggested by Patton (2002) and Bryman (2010). In this context, interviews with eighth-graders were first written down, and then these results were analyzed by researchers, music education specialists and program development specialists.

\section{Findings}

In order to determine the psycho-motor activities used by music teachers in the course, the eighth-graders who were interviewed were asked "What are the activities used in the course in general ?" and the following categories and themes were created regarding the answers given: 


\section{Table 1}

Category of Psychomotor Learning Activities Used in Music Lessons

\begin{tabular}{llll} 
Themes & Codes & $\mathrm{n}$ & $\%$ \\
\hline 1-Psychomotor activities & 1- Playing an instrument & 15 & 34.0 \\
& 2- Creating an instrument & 10 & 22.7 \\
& 3- Thump Out & 30 & 68,1 \\
& 4-Body Percussion & 35 & 79,5 \\
& 5- Singing & 44 & 100 \\
& & & \\
\hline 2- Cognitive Activities & 6- Exemplification & 25 & 56,8 \\
& 7- Listen to Music & 30 & 68.1 \\
& 8- Question-answer & 17 & 38,6 \\
\hline
\end{tabular}

Instrument playing, instrument creation, rhythm activities, body percussion and singing are specified as psychomotor activities used in music lessons by eighth graders (S1, S24, S27, S40, S18, S2, S23, S14, S20, S35, S41, S42, S43, S17, S37, S13, S19, S44, S15, S33), while sub-themes are identified as psycho-motor activities and cognitive activities after that the following student opinions are presented:

"... Sometimes the teacher gives us small instruments, asks us to keep a rhythm with them." (S 27)

"... Then we created a musical instrument ourselves. I made drums, put lentils in each bottle and shook them." (S 13)

"For example, there's thumping out. Snapping hands, foot-tapping, clapping." (S41)

"First we study, it's about the tune, then the piano plays, we sing. It's a lot of fun" (S 29)

"First the teacher lectures, then, writes some songs on the board, and then teaches us by playing the piano. For example, the rhythms. In this way, our teacher entertains us." (S 30)

Some eighth graders (S10, S9, S15, S34, S33, S19, S44, S5, S14) interviewed gave the following opinions under the theme of cognitive activities by sampling, listening to music and answering questions about the methods used by music teachers in the course.

"First, for example, she encrypts the lesson to get it into our minds better, it's like this, it's like this," she says. Then the teacher lectures the subject. Then she associates them to life." (S39)

"She plays music, for example, sometimes we always listen to music in class. She sets us free the whole lesson and never writes anything on the board." (S 8)

"We do Q\&A. ... We write questions on the board and then we solve the questions, we go and have them checked." (S 6)

"... She teaches nicely, she asks questions about subjects..." (S 23)

The 8th-grade students who were interviewed were asked about the methods and techniques used by music teachers during the lesson, what purpose they thought they were implementing 
psychomotor learning activities and how they felt during the activities, moreover the following themes were created about the answers given.

\section{Table 2}

Category of Student Opinions on Psychomotor Learning Activities

\begin{tabular}{llll} 
Themes & Codes & $\mathrm{n}$ & $\%$ \\
\hline $\begin{array}{l}\text { 1-Related to the Affective } \\
\text { Field Opinions }\end{array}$ & & 40 & 90,9 \\
& 1- It is fun & 15 & 34.0 \\
& 2- Relaxing & 10 & 22.7 \\
& 3- Ensures unity & & \\
& 4- The theoretical part & & 40,9 \\
& is boring & 18 & \\
& & & 56,8 \\
2-Related to the Cognitive & & & 27,2 \\
Field Opinions & 5-Pragmatical & 25 & 12 \\
& 6- Ensures persistency & &
\end{tabular}

Psychomotor activities that are practiced in music class are described by many 8th-graders (S6,

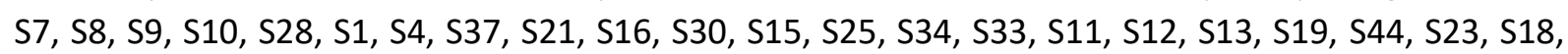
$\mathrm{S} 32, \mathrm{~S} 39, \mathrm{S2}, \mathrm{S} 5, \mathrm{~S} 14, \mathrm{~S} 24, \mathrm{~S} 38, \mathrm{~S} 22, \mathrm{~S} 26, \mathrm{~S} 31$ ) as sometimes fun and relaxing, sometimes boring, and the following student opinions are presented:

"It's fun, because it lightens difficulty of other lessons a little bit compared to other lessons. It is like toying. We like the lesson even more when we are close to the teacher." (S8)

"So music lessons take me to a different world. I relax. I love music lessons so much. I'm also listening music at home." (S 29)

"It is beneficial, it's fun, we chat in class, and we communicate with each other. It's a union." (S 40) "Sometimes it's boring when we write a lot, but at other events and stuff, it's fun, it's good when we sing." (S 15)

The educationality and permanence of psychomotor activities used in the music lesson are stated by many students (S1, S4, S37, S29, S21, S16, S30, S15, S25, S34, S33, S11, S12, S13, S19, S44, S23, S18, S32, S39, S10, S38, S24, S14, S5, S2, S9, S31, S26, S20) interviewed thereafter the following opinions are presented:

'I think it's very good, it's beautiful, we never get bored doing it and I think we learn better when we practice like that." (S 5)

"I think these activities should be practiced in every school. Because that's what you have to do to get a better understanding of the student. I think if that happens that way, we'll always figure everything out better and we won't forget." (D 32) 
Students who were interviewed were asked if there were any mishaps or difficulties that they spread in their own way during the implementation of the activities in the classroom and the following themes were created regarding the answers given.

\section{Table 3}

Category of Difficulties Encountered by Students

\begin{tabular}{|c|c|c|c|c|}
\hline Themes & Codes & $\mathrm{n}$ & & $\%$ \\
\hline \multirow{5}{*}{ 1- Scope and Content } & \multicolumn{4}{|l|}{ 1- Long time of the } \\
\hline & \multirow{2}{*}{\multicolumn{3}{|c|}{$\begin{array}{l}\text { theoretical part } \\
2 \text { - Failure of the appeal }\end{array}$}} & \multirow{4}{*}{22,7} \\
\hline & & & & \\
\hline & of activities & 10 & & \\
\hline & 3- Difficulty in solfeggio 10 & & 22,7 & \\
\hline \multirow[t]{4}{*}{ 2-Education situations } & 4- Difficulty in singing songs & 25 & & 56,8 \\
\hline & 5- Class noise and class size & 30 & & 68,1 \\
\hline & 6- Instrument deficiency & 17 & & 38,6 \\
\hline & 7- Absence of music class & 10 & & 22,7 \\
\hline
\end{tabular}

When the 8th-grade students are asked about the difficulties they face with psychomotor activities performed in the music class, it becomes clear that these are problems related to scope, content and educational status. Some of the 8th graders (S25, S33, S34, S4, S29, S21, S30, S15, S13, S18, S39) interviewed expressed their boredness with the theoretical part of the course, according to their opinions the activities sometimes did not appeal to them and that they had difficulty reading solfeggio, they offered the following opinions:

"... It's too long when writing and takes too much time. I get bored. I don't get bored singing or thumping out. It would be much better if it was always practice and not a theory." (S 34)

"... I don't like to practice it, especially on the body. Thumping out. But I like to thump out by hitting the table or with any tool... It's not only me, but also it's my other friends who don't do it most of the time. They don't like it, I guess." (S7)

"I have difficulty writing and reading notes. Especially on trebly notes and stuff." (S 30)

Some of the interviewed students $(\mathrm{S} 18, \mathrm{~S} 17, \mathrm{~S} 39, \mathrm{~S} 11, \mathrm{~S} 14, \mathrm{~S} 29, \mathrm{~S} 27)$ stated that they had difficulty performing the sound transitions in the songs sang during the lesson, added the other problems as; the noise in the classroom and also classroom size interrupt activities; the lack of instruments and the classroom environment negatively affect the course and they offered the following opinions:

"... I had a little trouble adjusting my voice. It was hard to go from high to low pitch, and low to high pitch." (S 18) 
"... But sometimes there's a lot of noise in the classroom, so we have a hard time singing the song. For example, we don't hear what we sing or the sound of the piano. Because some of our friends talk with each other, there is noise pollution and we can't really sing the music.' (S 2)

"... But we don't play instruments because we don't have instruments or place. There is no class for that. We might have the lesson in our own class, then it won't be like a music lesson.'

\section{Results, Discussion and Suggestions}

The students who participated in the study stated that the psychomotor learning activities used by music teachers in the course were playing instruments, creating instruments, keeping rhythms, body percussion and singing. They said that sometimes they use instruments to sing along with the teacher, and sometimes their teachers play the piano. All activities mentioned by students are included in music education programs as activities that are always used in music teaching and learning in basic, they are also applied in music classes. Students have specified the teaching methods frequently used by music teachers as exemplification, music playing and Q\&A. Although these methods seem to be more and primarily aimed at the cognitive field, it can be said that they are also capable of developing psychomotor and affective education with the practices in the continuation of the application of the methods.

These findings are similar to Aksu's (2007) study. Aksu (2007) emphasized that student-centered education and lifelong learning are partly done and also argued that music education is mostly teachercentered and with direct instruction methods, the greater use of psychomotor activities in lessons is important for the permanence of knowledge, in this way, attitudes towards music lessons will change.

According to their opinions on psychomotor activities, the students positively stated that these activities are fun, relaxing, and collaborative and they are bored with theoretical issues as a negative opinion. The fun and relaxing part of the music lesson indicates the characteristics that students develop in the affective field, this result is similar to the findings of Nacakcl (2006). Nacakcı (2006), in his research; found that primary school students generally displayed a positive attitude towards music lessons, while positive attitudes were collected in sub-dimensions such as activities, playing instruments and singing. Regarding the purposes of psychomotor activities, students have said that these activities are instructive and provide permanence in their learning. This result once again emphasizes to us that application-based learning remains in memory for a long time and is not easily forgotten.

Students discussed the challenges they face when practicing psychomotor skills development activities in terms of scope, content, and educational situations. Students said that they found the theoretical subjects included in the course boring and that they had difficulties about reading and writing musical notes. The fact that they have stated was they do not like to hit their bodies in body percussion practices, it can be said that the developmental characteristics of adolescence can be caused by what they feel. On the other hand, the fact that the voices have difficulty in performing the subtlety and thickness characteristics when singing can be cited as a reason why the students in this period are still in the mutating phase of their voices. The absence of music class, crowded classrooms and absence of instruments are other physical reasons that cause students to be unable to practice psychomotor activities. These findings are similar to those of Sağlam (2004) and Gürşen (2002).

Sağlam (2004) and Gürşen (2002) found that the music teachers do not use instruments in the course, that the songs selected in the courses are not suitable for the age and level of the students. They stated that the music class and equipment are missing in most schools, the music lesson time is inadequate, the music program used is not responding to the interests and needs of the students, the 
school administration does not support the music course. As a result, students do not come to the music class ready and motivated, and that the music course partially contributes to the cognitiveaffective and psychomotor development of the students.

Student opinions are important in highly practice-based courses such as music because the courses show a lot of student-centered features. Obtaining information by applying to student opinions during the preparation stages of course plans, curriculums and activities; will enable it to make the functioning of the content more realistic, robust, engaging and permanent. The age and developmental characteristics of the students are the most important points that the teacher should consider in music lessons. In music lessons, a course in which students use their bodies, hands, fingers and voices; especially the affective characteristics and psychomotor development should be examined in detail. Student needs, opinions and developmental characteristics should always be considered in increasing the interest and learning in the course and should not be ignored in any environment where learning continues in response, and it should be at the forefront of the agenda of the field of education in the future.

\section{References}

Aksu, C. (2007). Evaluation of the Level of Achievement of the Goals of the 8th Grade Music Program in Primary Education. (PhD Thesis). Ataturk University/Institute of Social Sciences, Erzurum.

Brown, J., Sherrill, C., \& Gench, B. (1981). Effects of an integrated physical education/music program in changing early childhood perceptual-motor performance. Perceptual and motor skills, 53(1), 151154.

Bryman, A. (2010). Social Research Methods (2. Baskı). Oxford University Press.

Concina, E. (2015). Music Education and Effective Teaching: Perspectives from a Critical. Research studies, 13(14), 15.

Çuhadar, H. (2016). Music and Music Education. Ç.Ü. Journal of the Social Sciences Institute, Vol.25 (1), 217-230.

Gorgoretti, B., Müezzinoğlu, A., Öztuğ, E., Bozkurt, B., Kiracıoğlu, B., Karagöz, B., \& Ulual, F. (2016). Music 1 Teacher's Handbook. Publication of TRNC Ministry of National Education and Culture.

Güleç, K. S. (2007). The importance of motivation in music education in terms of personal functions of music. Conference Statement. International Congress of Asian and North African Studies, Ankara

Gürşen, S. (2002). The Problems Encountered by Music Teachers Working in Primary and Secondary Education Institutions of the Ministry of National Education. (Unpublished Master Thesis). Marmara University/ Institute of Educational Sciences, Istanbul.

Jeong, J-E. (2005). Adaptation of Dalcroze methodology to the teaching of music to kindergarten students in Korea. D.M.A. dissertation. Boston University, Massachusetts.

Karakoç, E., \& Şendurur, Y. (2015). The Reflection of Özengen Music Education in Primary Schools on Students' Musical Behaviors. Çankırı Karatekin University Journal of Social Sciences Institute, 6(1), 277 290. 
Lewis, B. (1989). The research literature in movement-based instruction with children: Implications for music teaching and learning. Update: Applications of Research in Music Education, 7(2), 13-17.

Nacakcl, Z. (2006). Attitudes of Primary School Students towards Music Lesson. Proceeding of the National Music Education Symposium. Pamukkale University Faculty of Education, Denizli.

Patton, Q. M. (2002). Qualitative Research \& Evaluation Methods. Sage Publications.

Petress, K. (2005). The Importance of Music Education. Education, 126(1).

Pflederer, M. (1964). The responses of children to musical tasks embodying Piaget's principle of conservation. Journal of Research in Music Education, 12, 251-268.

Richards, M. H. (2015). The Legacy from Kodály. Music Educators Journal. Vol. 49, No.6. 27-30.

Sağlam, H. (2004). Opinions of Music Teachers Working in Primary Education Institutions on the Second Cycle Curriculum of Primary Education Institutions Music Lessons. Gazi University, Institute of Educational Sciences, Ankara.

Soykunt, N., \& Gorgoretti, B. (2019). Views of Music Teachers on Psycho-Motor Activities. Journal of History Culture and Art Research, 8(1), 100-110. http://dx.doi.org/10.7596/taksad.v8i1.1769

Türnüklü, A. (2000). A qualitative research technique that can be used effectively in educational research: Interview. Educational administration in theory and practice, 24(24), 543-559.

Uçan, A. (1997). Music Education, Basic Concepts-Principles-Approaches (2nd Edition) Music Encyclopedia Publications.

Yıldırım, A., \& Şimşek, H. (2016). Qualitative research methods in the social sciences. Distinguished. 